\title{
Experimental and modelling studies on the uncatalysed thermal conversion of inulin to 5-hydroxymethylfurfural and levulinic acid
}

\author{
B A Fachri ${ }^{1,3}$, R M Abdilla ${ }^{1}$, C B Rasrendra ${ }^{2}$ and H J Heeres ${ }^{1 *}$
}

\begin{abstract}
Background: 5-Hydroxymethylfurfural (HMF), an important biobased platform chemical, is accessible by the acid catalysed conversion of biopolymers containing hexoses (cellulose, starch, inulin) and monomeric sugars derived thereof. We here report an experimental study on the uncatalysed, thermal conversion of inulin to HMF in aqueous solutions in a batch set-up.

Results: The reactions were conducted in a temperature range of $153-187^{\circ} \mathrm{C}$, an inulin loading between 0.03 and $0.12 \mathrm{~g} / \mathrm{mL}$ and batch times between 18 and 74 min using a central composite experimental design. The highest experimental HMF yield in the process window was $35 \mathrm{wt} \%$ (45 mol\%), which is $45 \%$ of the theoretical maximum (78 wt\%). The HMF yields were modeled using a statistical approach and good agreement between experiment data and model was obtained. The possible autocatalytic role of formic acid (FA) and levulinic acid, two main byproducts, was probed by performing reactions in the presence of these acids and it was shown that particularly FA acts as a catalyst.
\end{abstract}

Conclusions: Inulin is an interesting feed for the synthesis of HMF in water. A catalyst is not required, though autocatalytic effects of FA play a major role and also affect reaction rates and product yields.

\section{Graphical abstract:}

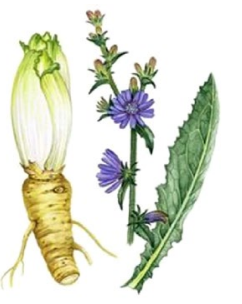

Chicory

\section{Inulin}

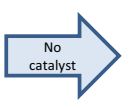

$\mathrm{HO}$<smiles>O=Cc1ccc(CO)o1</smiles>

5-hydroxymethylfurfural

Keywords: Inulin, HMF, Thermal reaction, Autocatalytic effects

\footnotetext{
*Correspondence: h.j.heeres@rug.nl

${ }^{1}$ Chemical Engineering Department, University of Groningen, Nijenborgh

4, 9747 AG Groningen, The Netherlands

Full list of author information is available at the end of the article
}

\section{Chemistry Central \\ (C) 2015 Fachri et al. This article is distributed under the terms of the Creative Commons Attribution 4.0 International License (http://creativecommons.org/licenses/by/4.0/), which permits unrestricted use, distribution, and reproduction in any medium, provided you give appropriate credit to the original author(s) and the source, provide a link to the Creative Commons license, and indicate if changes were made. The Creative Commons Public Domain Dedication waiver (http://creativecommons.org/ publicdomain/zero/1.0/) applies to the data made available in this article, unless otherwise stated.}




\section{Background}

Biomass has been identified as an attractive alternative for crude oil, natural gas and coal to produce fuels and chemicals. When considering biobased chemicals, particularly the carbohydrate fraction (cellulose and hemicellulose) of lignocellulosic biomass shows high potential. An example of a biobased chemical is 5-hydroxymethylfurfural (HMF), which has been classified as one of the top 12 biobased chemical from biomass by the US department of Energy (DOE) [1,2]. HMF is a very versatile building block for biofuels or biofuel additives [3, 4], solvents, surface-active agents, fungicides [5] and for interesting monomers for the plastics industry $[1,6,7]$.

5 -Hydroxymethylfurfural may be synthesised from of a wide range of hexoses by elimination of three water molecules (Scheme 1, example for D-fructose).

Conventionally, the reaction is carried out in water using a Brönsted acid with D-fructose as the preferred carbohydrate source [8-20]. Hydrochloric acid and sulfuric acid are the most commonly used Brönsted acids. Kuster [21], reported that D-fructose is more reactive and selective towards to HMF than D-glucose and a HMF yield from D-fructose of $68 \%$ was reported using $\mathrm{HCl}$ as the catalyst $\left(\mathrm{C}_{\text {fruct }}=9 \mathrm{wt} \%, 1.5 \mathrm{~h}\right)$. Yields in water are less than quantitative due to the formation of insoluble byproducts (humins) and a subsequent reaction of HMF to levulinic acid (LA) and formic acid (FA, Scheme 1). Two main reaction mechanisms have been proposed for the reaction in water, one involving acyclic intermediates and another with cyclic intermediates [22].

Considerable progress has been made to enhance HMF yields, among others by using solvents other than water and the use of advanced catalysts [8]. Typical homogeneous Brönsted catalysts (mineral acids) have the advantage that they are relatively cheap, though recycling is often cumbersome. As such, heterogeneous catalysts could be beneficial and have been tested in detail. However, catalyst lifetime needs to be established and a major concern is the deposition of humin substances on the heterogeneous catalysts leading to irreversible catalyst deactivation. Examples of solvents other than water tested for the reaction include acetone [17], methanol [17], toluene [23] and dimethyl sulfoxide (DMSO) [24]. Among them, reactions in DMSO give essentially quantitative HMF yields [8], though down-stream processing is considerably more complicated than with water and is a critical issue.

Despite these advances, efficient, economically viable routes to produce HMF from D-fructose have not yet been commercialised. Bicker et al. [17] estimated an HMF cost price of $2 € / \mathrm{kg}$, using the assumption that $\mathrm{D}$-fructose is available at a price of $0.5 € / \mathrm{kg}$. Torres et al., [25] reported that the manufacturing costs of HMF are between 1.97 and $2.43 \$ / \mathrm{kg}$, depending on the solvent used, based on a D-fructose price of $0.55 \$ / \mathrm{kg}$ and 7000 ton/year HMF production unit. An HMF price of around $1.00 \$ / \mathrm{kg}$ is considered a good starting point to allow its use in bulk-scale chemical applications.

The major variable cost item in the economic evaluations for HMF manufacture is the cost of the D-fructose feed. As such, the identification of low priced D-fructose alternatives is of high importance for the development of techno-economically viable routes to HMF. Alternative feeds are biopolymers enriched in D-fructose units, which are likely cheaper than purified D-fructose. An interesting biopolymer is inulin, an oligosaccharide consisting of mainly fructose units, in some cases capped with a glucose unit $[6,15,26]$. Inulin can be extracted from plants, examples are jerusalem artichoke [27-31], chicory [28-31] and dahlia tubers [28-31]. Of particular interest are the Jerusalem artichoke and chicory, which are reported to have a high inulin content of up to $20 \%$ on fresh weight [32].

A number of studies have been performed on the catalysed inulin conversion to HMF in water, the solvent of choice in the current investigation (Table 1). Temperatures are typically between 80 and $200^{\circ} \mathrm{C}$, reaction times vary between minutes and $3 \mathrm{~h}$, and intakes of inulin are between 5 and $10 \mathrm{wt} \%$ on solvent. A range of catalysts has been applied, varying form homogeneous $\left(\mathrm{H}_{2} \mathrm{CO}_{3}\right.$, formed in situ by $\mathrm{CO}_{2}$ addition) to heterogeneous catalysts. Reactions not only have been performed in water but also in water-organic solvent mixtures and ionic<smiles>CC(=O)CCC(=O)O</smiles> 
Table 1 Overview of HMF yield data for the catalysed conversion of Inulin to HMF in water

\begin{tabular}{|c|c|c|c|c|c|c|}
\hline$C_{\text {inulin }}(w t \%)$ & $\mathrm{T}\left({ }^{\circ} \mathrm{C}\right)$ & $\mathrm{t}$ & Catalyst & Catalyst loading & HMF yield (\%) & References \\
\hline \multicolumn{7}{|c|}{ Water/homogeneous catalyst } \\
\hline 5 & 160 & $4 \min$ & $\mathrm{CO}_{2}$ & $6 \mathrm{MPa}$ & $45^{b}$ & {$[34]$} \\
\hline 5 & 160 & $4 \min$ & $\mathrm{CO}_{2}$ & $9 \mathrm{MPa}$ & $42^{b}$ & {$[34]$} \\
\hline 5 & 180 & $2 \min$ & $\mathrm{CO}_{2}$ & $4 \mathrm{MPa}$ & $45^{\mathrm{b}}$ & {$[34]$} \\
\hline 5 & 180 & $2 \min$ & $\mathrm{CO}_{2}$ & $6 \mathrm{MPa}$ & $50^{b}$ & [34] \\
\hline 5 & 180 & $2 \min$ & $\mathrm{CO}_{2}$ & $11 \mathrm{MPa}$ & $52^{b}$ & {$[34]$} \\
\hline 5 & 200 & $45 \mathrm{~min}$ & $\mathrm{CO}_{2}$ & $6 \mathrm{MPa}$ & $53^{b}$ & {$[34]$} \\
\hline 5 & 200 & $45 \mathrm{~min}$ & $\mathrm{CO}_{2}$ & $9 \mathrm{MPa}$ & $49^{b}$ & {$[34]$} \\
\hline \multicolumn{7}{|c|}{ Water/solid catalyst } \\
\hline 6 & 100 & $0.5 \mathrm{~h}$ & Cubic $\mathrm{ZrP}_{2} \mathrm{O}_{7}$ & $0.6 \mathrm{~g}$ & $26(w t \%)$ & {$[35]$} \\
\hline 6 & 100 & $1 \mathrm{~h}$ & Cubic $\mathrm{ZrP}_{2} \mathrm{O}_{7}$ & $0.6 \mathrm{~g}$ & 35 (wt\%) & {$[35]$} \\
\hline 6 & 100 & $2 \mathrm{~h}$ & Cubic- $\mathrm{ZrP}_{2} \mathrm{O}_{7}$ & $0.6 \mathrm{~g}$ & $36(w t \%)$ & {$[35]$} \\
\hline 6 & 100 & $1 \mathrm{~h}$ & $\mathrm{Ti}\left(\mathrm{PO}_{4}\right)\left(\mathrm{H}_{2} \mathrm{PO}_{4}\right) \cdot 2 \mathrm{H}_{2} \mathrm{O}$ & $0.6 \mathrm{~g}$ & 41 (wt\%) & {$[35]$} \\
\hline 6 & 100 & $2 \mathrm{~h}$ & $\mathrm{Ti}\left(\mathrm{PO}_{4}\right)\left(\mathrm{H}_{2} \mathrm{PO}_{4}\right) \cdot 2 \mathrm{H}_{2} \mathrm{O}$ & $0.6 \mathrm{~g}$ & 65 (wt\%) & {$[35]$} \\
\hline 6 & 80 & $2 \mathrm{~h}$ & FeVOP & $5 w t \%$ & 35 (mol\%) & {$[36]$} \\
\hline 10 & 155 & $18 \mathrm{~min}$ & $\mathrm{HNb}_{3} \mathrm{O}_{8}$ & $\mathrm{SCR}=50$ & 43 (mol\%) & {$[37]$} \\
\hline 6 & 100 & $3 \mathrm{~h}$ & Niobium phosphate & $\mathrm{SCR}=1.6$ & 31 (mol\%) & {$[38]$} \\
\hline
\end{tabular}

SCR substrate to catalyst ratio.

a wt or mol in brackets after entries.

b $w t \%$ or mol\% not provided.

liquids. Highest HMF yields (88 mol\% on inulin) were reported by Hu et al. [33] using DMSO as the solvent.

We here report a study on the conversion of inulin to HMF using water as the solvent in the absence of a catalyst. In this way, catalyst recycle procedures are eliminated and drawbacks of heterogeneous catalysts (among others deactivation by humin deposition) are avoided. Water was selected as the solvent of choice, as it is environmentally benign, is a good solvent for many carbohydrates and it is cheap, nontoxic, and nonflammable [39-42].

A number of studies have been reported on the uncatalysed conversion of D-fructose to HMF (Table 2). For inulin, very limited information is available in the literature. The only paper is by Wu et al. [34] who reported an HMF yield of $48 \%\left(200^{\circ} \mathrm{C}\right.$, inulin loading of $5 \mathrm{wt} \%$ and $1 \mathrm{~h}$ reaction time).

Thus, it can be concluded that a detailed study on the effect of process conditions on HMF yields for the thermal decomposition of inulin in water has not been reported to date. We here report a systematic study on the effect of process conditions like reaction time, inulin intake and reaction temperature on the HMF yield. A total of 24 batch experiments were performed using a composite design. The data were analysed statistically and a model was developed to describe the HMF yield versus process conditions. Finally, possible autocatalytic effects of organic acids (FA and LA) on the rates of reactions and HMF yields were explored.
Table 2 Overview of studies for the uncatalysed reaction of D-fructose and inulin to HMF in water

\begin{tabular}{|c|c|c|c|c|c|}
\hline Substrate & $\begin{array}{l}\text { Substrate } \\
\text { intake (wt\%) }\end{array}$ & $\mathrm{T}\left({ }^{\circ} \mathrm{C}\right)$ & $\mathbf{t}$ & Yield (\%) & References \\
\hline \multirow[t]{10}{*}{ D-Fructose } & 4.5 & 175 & $45 \mathrm{~min}$ & $56^{c}$ & {$[14]$} \\
\hline & 5 & 140 & $1 \mathrm{~h}$ & $4(\mathrm{~mol} \%)$ & {$[16]$} \\
\hline & 9 & 200 & $5 \mathrm{~min}$ & 41 (mol\%) & [18] \\
\hline & 30 & $160^{a}$ & $5 \mathrm{~min}$ & 1 (mol\%) & {$[43]$} \\
\hline & 30 & $190^{\mathrm{a}}$ & $5 \mathrm{~min}$ & 36 (mol\%) & {$[43]$} \\
\hline & 2 & $200^{a}$ & $5 \mathrm{~min}$ & 13 (mol\%) & {$[44]$} \\
\hline & 30 & 170 & $3 \mathrm{~h}$ & 43 (mol\%) & {$[45]$} \\
\hline & $0.05^{d}$ & 240 & $3 \mathrm{~min}$ & $20^{c}$ & {$[54]$} \\
\hline & 5 & 125 & $5 \min$ & $0.8^{c}$ & {$[56]$} \\
\hline & 11 & 200 & $30 \mathrm{~min}$ & $51^{c}$ & {$[57]$} \\
\hline \multirow[t]{3}{*}{ Inulin } & 5 & 160 & $4 h$ & $38^{c}$ & {$[34]$} \\
\hline & 5 & 180 & $2 \mathrm{~h}$ & $41^{c}$ & {$[34]$} \\
\hline & 5 & 200 & $1 \mathrm{~h}$ & $48^{c}$ & {$[34]$} \\
\hline
\end{tabular}

a Heating by microwave irradiation.

b wt or mol in brackets after entries.

c wt $\%$ or mol\% not provided.

d In molar.

\section{Experimental section}

\section{Chemicals}

Inulin from Dahlia tubers was purchased from Acros Organic (Geel, Belgium). D-Fructose (99\%) and LA 
$(\geq 97 \%)$ were obtained from Acros Organic (Geel, Belgium). Formic acid ( $\geq 95 \%)$ and D-glucose $(\geq 99.5 \%)$ were purchased from Merck KGaA (Darmstadt, Germany). HMF ( $\geq 99 \%)$ was obtained from Sigma Aldrich (Steinheim, Germany). 2,5-Dihydroxybenzoic acid (DHB) $(\geq 99 \%)$ was purchased from Fluka (Deisenhofen, Germany). All chemicals were used without purification. Deionized water was used to prepare the solutions.

\section{Experimental procedures}

The experimental procedures are based on previous research by our group (Girisuta et al. [19]). In a typical experiment, the pre-determined amount of inulin and deionized water $(4 \mathrm{~mL})$ were loaded to glass ampoules with an internal diameter of $5 \mathrm{~mm}$, a length of $15 \mathrm{~cm}$ and thickness of $1.5 \mathrm{~mm}$. The ampoules were sealed with a torch.

For the exploratory experiments, a series of ampoules was placed in a rack in a heating oven (Heraeus Instruments Type UT6060) at constant temperature. At different reaction times, an ampoule was taken from the oven and quickly quenched in cold water to stop the reaction. The experiments carried out in the framework of the experimental design were individually performed in an oven (Heraeus Instruments Type UT6060) at the pre-set temperature. For the autocatalytic experiments with LA and FA, a series of ampoules were filled with inulin $(0.1 \mathrm{~g} / \mathrm{mL})$ and the appropriate amount of each acid $(0$ or $0.1 \mathrm{M})$ and placed in an oven [Binder, APT Line $\left.{ }^{\mathrm{ma}} \mathrm{FD}(\mathrm{E} 2)\right]$ at $180^{\circ} \mathrm{C}$ for a predetermined reaction time. The experiments were repeated at different reaction times allowing construction of an HMF yield versus time plot for each individual organic acid and the blank experiment. All experiments were conducted in duplicate and the average value is taken. The outcome of the autocatalytic experiments cannot be compared directly with that of the screening and experimental design experiments as the heating up profile (temperature versus time) for both ovens differs.

After reaction, the ampoules were opened and the reaction mixture was taken out, and centrifuged for about 10-30 min to remove the solids. The liquid product was diluted with demi water before analysis.

The composition of the inulin sample and particularly the type and amount of $\mathrm{C}_{6}$-sugars was determined by an acid-catalysed hydrolysis reaction. For this purpose, inulin $(2.5 \mathrm{~g})$ was dissolved at $70^{\circ} \mathrm{C}$ in $150 \mathrm{~mL}$ of water under stirring. The $\mathrm{pH}$ was adjusted to $1.4-1.6$ by adding $\mathrm{HCl}$ $(12 \mathrm{M})$. Then, the solution was placed in a water-bath for $30 \mathrm{~min}$ at $90^{\circ} \mathrm{C}$. A liquid sample was taken and analysed by HPLC.

\section{Analysis}

Matrix assisted laser desorption ionization-time of flight mass spectrometry (MALDI-TOF MS) on a Voyager-DE
PRO was used to determine the molecular weight of the inulin sample. DHB was used as the matrix.

HPLC was used to identify and quantify the liquid product from the reactions. The HPLC system consisted of a Hewlett Packard 1050 pump, a Bio-Rad organic acid column Aminex HPX-87H and a Water 410 differential refractive index detector. A sulfuric acid solution $(5 \mathrm{mM})$ was used as the eluent with a constant flow rate of about $0.55 \mathrm{~cm}^{3} / \mathrm{min}$. The column was operated at $60^{\circ} \mathrm{C}$. The HPLC was calibrated with solutions of the pure compounds at a range of concentrations. Using the chromatogram peak area and the external calibration curves, the concentrations of components in the liquid phase were determined.

\section{Definitions}

The HMF yield ( $\left.\mathrm{y}_{\mathrm{HMF}}\right)$ is defined according to Eq. (1) and reported on a weight basis.

$$
\mathrm{y}_{\mathrm{HMF}}=\frac{\mathrm{C}_{\mathrm{HMF}} \times \mathrm{M}_{\mathrm{HMF}} \times \mathrm{V}}{\mathrm{W}_{\mathrm{In}}} \times 100 \%(\mathrm{wt} \%)
$$

here, $\mathrm{C}_{\mathrm{HMF}}$ represents HMF concentration $(\mathrm{mol} / \mathrm{L})$ at a certain time $\mathrm{t}, \mathrm{M}_{\mathrm{HMF}}$ is the molecular weight of $\mathrm{HMF}$ (g/ $\mathrm{mol}), \mathrm{V}$ represents the liquid volume $(\mathrm{L})$ and $\mathrm{w}_{\text {in }}$ represents the intake of inulin (g).

The yield of HMF was converted from wt $\%$ to mol\% by assuming that inulin consists of linked glucose/fructose units $\left(\mathrm{C}_{6} \mathrm{H}_{10} \mathrm{O}_{5}\right)$ which react to HMF according to the following stoichiometry:

$$
\mathrm{C}_{6} \mathrm{H}_{10} \mathrm{O}_{5} \rightarrow \mathrm{C}_{6} \mathrm{H}_{6} \mathrm{O}_{3}+2 \mathrm{H}_{2} \mathrm{O}
$$

As such, the maximum yield of HMF is $78 \mathrm{wt} \%$. Thus, the yield of HMF in mol\% may be calculated from the yield in $w t \%$ by dividing the latter by 0.78 .

\section{Statistical modelling}

The optimisation experiments were modeled using Design-Expert 7 software (Stat-Ease). The yield of HMF $\left(\mathrm{Y}_{\mathrm{HMF}}\right)$ was modeled using a standard expression as given in Eq. (3):

$$
\mathrm{y}_{\mathrm{HMF}}=b_{o}+\sum_{i=1}^{3} b_{i} x_{i}+\sum_{i=1}^{3} \sum_{j=1}^{3} b_{i j} x_{i} x_{j}
$$

The independent variables (inulin intake, temperature and reaction time) are represented by the indices $1-3$. The regression coefficients were obtained by statistical analyses of the data. Significance of factors was determined by their $p$ value in the ANOVA analyses. A factor was considered significant if the $p$ value was lower than 0.05 , meaning that the probability of noise causing the correlation between a factor and the response is lower than $5 \%$. Insignificant factors were eliminated using 
backward elimination, and the significant factors were used to model the data.

\section{Result and discussion}

\section{Inulin characterization}

The molecular weight distribution of the inulin used in this study (Dahlia tubers) was determined by MALDITOF/MS, a technique particularly suited for molecular weight determinations of oligosaccharides and polysaccharides [46, 47]. The $M_{n}$ was found to be 2560 , the $M_{w}$ 3680 , indicating an average degree of polymerisation (DP) of about 16. Roberfroid [31] reported that the DP of inulin varies according to plant species, weather conditions, and the physiological age of the plant. In chicory, DP values range from 2 to 65 , with 15 reported as an average. For inulin from onions, the DP is in the range of 2-12, for Jerusalem artichoke the DP is reported to be $<40$. Thus, the experimentally determined value of the DP of the inulin sample used in this study is within the ranges reported in the literature.

The D-fructose and D-glucose content of the inulin used in this study were determined by a mild hydrolysis of the samples followed by HPLC analyses of the liquid phase. The fructose content was $94 \mathrm{~mol} \%$, the remainder being glucose, giving a fructose to glucose ratio of 15-1. The fructose content is in close agreement with the literature for Dahlia tubers (94.1-96.7 mol\%) [48]. Thus, the inulin sample contains mainly of oligomers with D-fructoside units, with each oligomer chain on average capped with a D-glucose molecule, in line with literature data [31].

\section{HMF synthesis from inulin in the absence of a catalyst}

Exploratory experiments on the thermal conversion of inulin were performed at $170^{\circ} \mathrm{C}$, using an inulin intake of $0.1 \mathrm{~g} / \mathrm{mL}$. A typical concentration profile is given in Figure 1. Six water soluble components were identified in the reaction mixtures (HPLC). Three show a clear maximum in the course of the reaction, viz. D-fructose, D-glucose and HMF, and are as such intermediates in the reaction sequence. The final products are LA, FA and acetic acid (AA). In addition, some brown-black insolubles were observed, known as humins, which are always formed during the acid catalysed conversions of carbohydrates in water, either in monomeric or polymeric form [8].

The product composition versus time is in agreement with the reaction network provided in Scheme 2. It involves the saccharification of inulin to the monomeric building blocks (D-fructose and some D-glucose), followed by the reaction of these C6 sugars to HMF. The latter is not inert under reaction conditions and reacts further to LA and FA $[18,19,49-52]$.

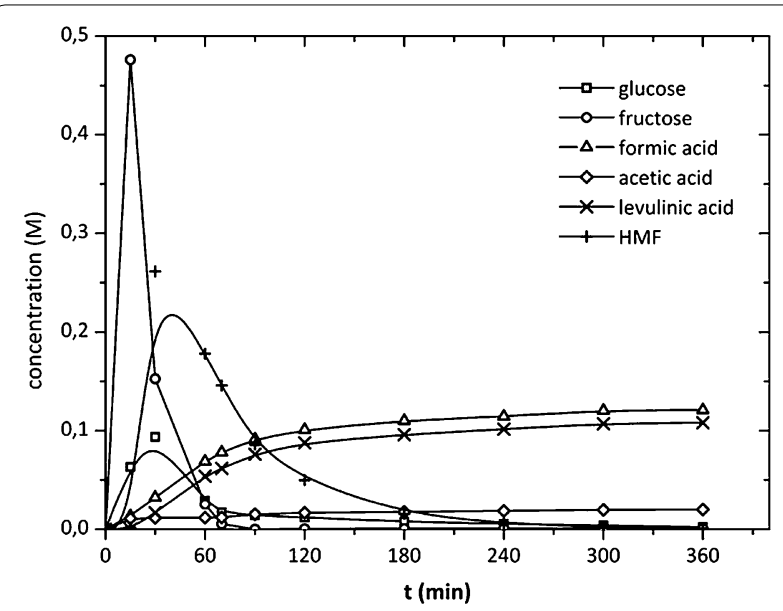

Figure 1 Concentration-time profiles for various compounds during the thermal conversion of inulin in water $\left(170^{\circ} \mathrm{C}, C_{\ln }=0.1 \mathrm{~g} / \mathrm{mL}\right)$.

Besides these products, acetic acid was detected in small amounts, though not quantified. AA is likely formed by hydrolysis of acetyl side groups in the inulin [53] or alternatively, from further degradation reactions of the intermediates. For instance, Asghari et al. [54] reported the formation of acetic acid ( $5 \mathrm{~mol} \%)$ from fructose in subcritical water $\left(200-320^{\circ} \mathrm{C}\right.$, residence time of $120 \mathrm{~s}, \mathrm{C}_{\text {fruct }}$ of $0.05 \mathrm{M}$, no catalyst).

\section{Effect of process conditions of the uncatalysed conversion of inulin to HMF}

To determine and quantify the effect of process variables on the conversion of HMF, 24 experiments were conducted in a batch reactor set up (glass ampoules) using a central composite design. Three independent variables, the temperature $\left(153-187^{\circ} \mathrm{C}\right)$, inulin intake $(0.03-0.12 \mathrm{~g} /$ $\mathrm{mL}$ ) and reaction time (18-74 $\mathrm{min})$, were explored and the yields of HMF and LA were taken as the dependent variables. The results are provided in Table 3.

The center point of the central composite design was measured six times and the HMF yield was found to be on average $21.4 \mathrm{wt} \%$ with a standard deviation of $2.9 \mathrm{wt} \%$. Thus, the reproducibility of the experimental procedure appears to be good.

The highest experimental HMF yield was about $35 \mathrm{wt} \%$ (45 mol\%, entry 6 in Table 3) and was achieved at $180^{\circ} \mathrm{C}$, an inulin intake of $0.05 \mathrm{~g} / \mathrm{mL}$ and a reaction time of $18 \mathrm{~min}$. Wu et al. [34] reported an $\mathrm{HMF}$ yield of $41 \%$ at $180^{\circ} \mathrm{C}$, an inulin intake of $0.05 \mathrm{~g} / \mathrm{mL}$ and a reaction time of $2 \mathrm{~h}$. Comparison is cumbersome as conditions are not exactly similar and different starting materials were used (among others, inulin source and related properties like DP).

It is also of interest to compare the results with those obtained for inulin in water with sulphuric acid as the 


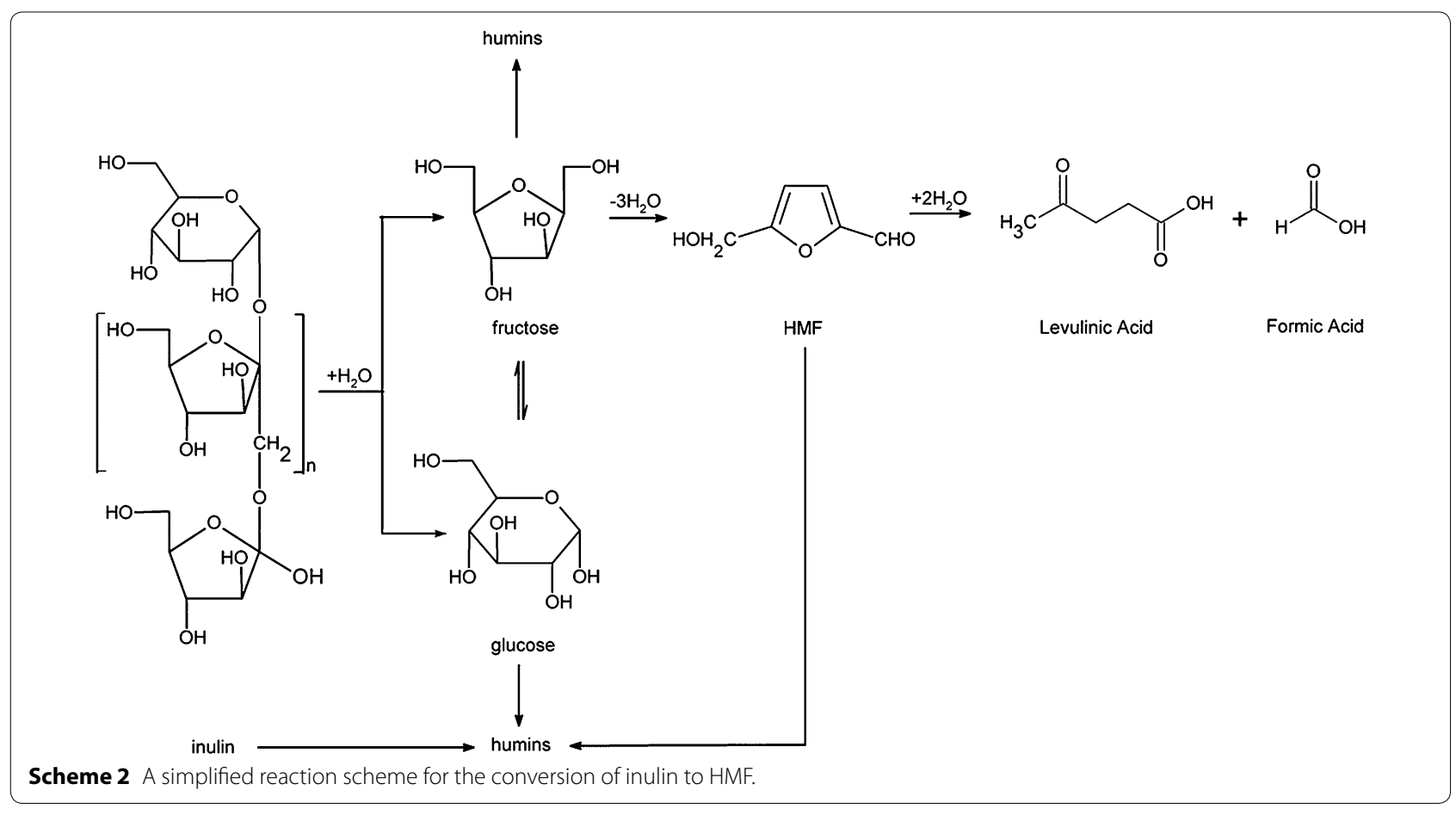

Table 3 Overview of experiments for the thermal, uncatalysed conversion of inulin to HMF and LA

\begin{tabular}{llllcc}
\hline Run & $\mathbf{C}_{\text {in }}(\mathbf{g} / \mathbf{m L})$ & $\mathbf{T}_{\text {reaction }}\left({ }^{\circ} \mathbf{C}\right)$ & $\mathbf{t}(\mathbf{m i n})$ & $\mathbf{y}_{\mathbf{H M F}}(\mathbf{w t} \%)$ & $\mathbf{y}_{\mathbf{L A}}(\mathbf{w t} \%)$ \\
\hline 1 & 0.08 & 170 & 39 & 22.8 & 4.0 \\
2 & 0.05 & 160 & 18 & 2.7 & - \\
3 & 0.08 & 170 & 39 & 23.1 & 3.1 \\
4 & 0.08 & 170 & 39 & 23.9 & 3.2 \\
5 & 0.05 & 180 & 18 & 32.1 & 5.6 \\
6 & 0.05 & 180 & 18 & 35.0 & 6.1 \\
7 & 0.12 & 170 & 39 & 17.6 & 6.1 \\
8 & 0.08 & 170 & 39 & 23.1 & 3.3 \\
9 & 0.08 & 187 & 39 & 14.6 & 13.4 \\
10 & 0.08 & 170 & 39 & 22.5 & 1.1 \\
11 & 0.08 & 170 & 39 & 21.8 & 1.5 \\
12 & 0.08 & 170 & 39 & 19.4 & 1.8 \\
13 & 0.08 & 170 & 39 & 16.6 & 2.2 \\
14 & 0.08 & 170 & 74 & 8.9 & 1.9 \\
15 & 0.1 & 180 & 18 & 20.9 & 5.5 \\
16 & 0.03 & 170 & 39 & 24.8 & 3.6 \\
17 & 0.05 & 160 & 60 & 25.7 & 3.1 \\
18 & 0.1 & 160 & 60 & 23.3 & 3.6 \\
19 & 0.1 & 160 & 18 & 3.2 & - \\
20 & 0.05 & 180 & 60 & 10.1 & 9.4 \\
21 & 0.05 & 180 & 60 & 10.4 & 9.0 \\
22 & 0.1 & 180 & 60 & 3.1 & 9.5 \\
23 & 0.1 & 180 & 60 & 2.2 & 9.8 \\
24 & 0.08 & 153 & 39 & 12.4 & 0.3 \\
\hline & & & & &
\end{tabular}

catalyst [55]. In the latter case, the highest experimental yield of HMF was $39.5 \mathrm{wt} \%$ (50.6 mol\%), obtained at $170^{\circ} \mathrm{C}, 0.17 \mathrm{~g} / \mathrm{mL}$ inulin intake and an acid concentration of $0.006 \mathrm{M}$ and $20 \mathrm{~min}$ reaction time. Thus, the maximum HMF yield for the uncatalysed, thermal reaction within the window of process conditions is only slightly lower than when using a Brönsted acid. The reaction time is in general much longer for the thermal reaction than for the sulphuric acid catalysed reaction. As such, the use of a Brönsted acid catalyst has advantages in terms of reaction rates and as such a smaller reactor will be needed to achieve a certain production rate $(\mathrm{kg} / \mathrm{h})$. However, sulphuric acid recycle, complicating the work-up section, is not required for the uncatalysed reaction. Detailed process design studies will be required for both options to evaluate the best approach and these are beyond the scope of the current study.

\section{Statistical modeling}

The HMF yield $\left(\mathrm{y}_{\mathrm{HMF}}\right)$ as a function of the independent variables was statistically modelled using the DesignExpert 7 software package. All independent variables (temperature $\mathrm{T}$, intake inulin $\mathrm{C}_{\mathrm{in}}$ and reaction time $\mathrm{t}$ ) were shown to be statistically significant and to have an effect on the HMF yield. The best model for HMF yield is given in Eq. (4) and includes both quadratic and interaction terms. An extended version with more significant numbers for the coefficients to be used for among others 
reactor engineering studies is given in the Additional file 1 . The R-squared of the model is 0.9664 , an indication that the model fits the experimental data well.

$$
\begin{aligned}
\mathrm{y}_{\mathrm{HMF}}= & (1466.7) \mathrm{C}_{\mathrm{in}}+(11.8) \mathrm{T}+(9.3) \mathrm{t}-(9.2) \mathrm{C}_{\mathrm{in}} \mathrm{T} \\
& -(0.05) \mathrm{tT}-(0.03) \mathrm{T}^{2}-(0.009) \mathrm{t}^{2}-1223.9
\end{aligned}
$$

Analysis of the model variance is given in Table 4. A good agreement between the model and the experimental data was observed, as is shown in the parity plot provided in Figure 2.

With the statistical model available, it is possible to determine the effects of the process conditions on the HMF yield within the design window. To illustrate this, the model predictions for HMF yield for batch times of $30 \mathrm{~min}$ (Figure 3, left) and $40 \mathrm{~min}$ (Figure 3, right) are given versus the temperature and inulin intake. The yield of HMF is a complex function of the independent variables and it is difficult to draw general conclusions. Though, as expected, the HMF yields after $40 \mathrm{~min}$

\begin{tabular}{|c|c|c|c|c|c|}
\hline Source & Sum of squares & df & Mean square & F value & $\begin{array}{l}\text { p value } \\
\text { Prob }>\text { F }\end{array}$ \\
\hline Model & $1,878.14$ & 7 & 268.31 & 65.66 & $<0.0001$ \\
\hline$C_{\text {in }}(A)$ & 85.20 & 1 & 85.20 & 20.85 & 0.0003 \\
\hline $\mathrm{T}(\mathrm{B})$ & 50.63 & 1 & 50.63 & 12.39 & 0.0028 \\
\hline$t(C)$ & 2.27 & 1 & 2.27 & 0.56 & 0.4665 \\
\hline$A B$ & 55.60 & 1 & 55.60 & 13.61 & 0.0020 \\
\hline$B C$ & $1,156.24$ & 1 & 1156.24 & 282.96 & $<0.0001$ \\
\hline$B^{2}$ & 107.51 & 1 & 107.51 & 26.31 & 0.0001 \\
\hline$C^{2}$ & 159.51 & 1 & 159.51 & 39.04 & $<0.0001$ \\
\hline Residual & 65.38 & 16 & & & \\
\hline
\end{tabular}

Table 4 Analysis of variance of the HMF model

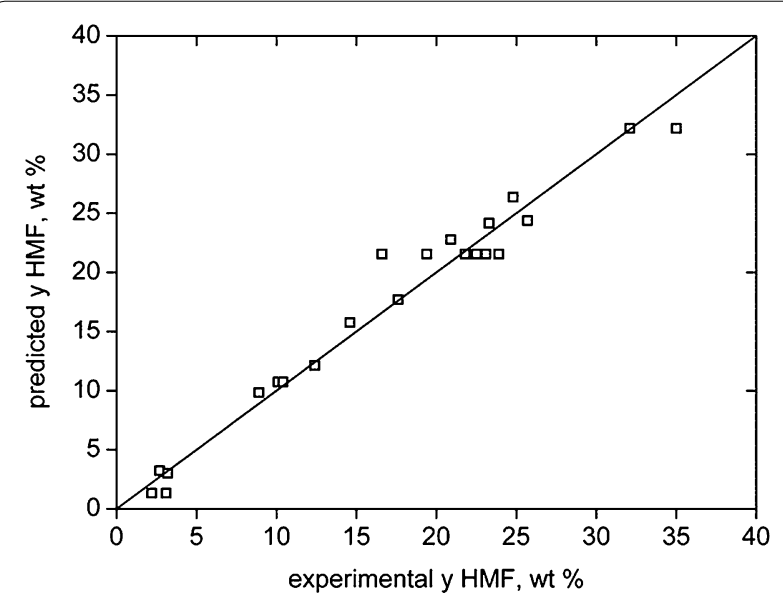

Figure 2 Parity plot between the experimental and modelled HMF yields. are lower than for $30 \mathrm{~min}$. This is due to the subsequent reaction of HMF to LA and FA (Scheme 2), leading to a lowering in the HMF yield. The effect of the inulin intake on the HMF yield is also complex in nature and temperature depending. At low temperatures, the HMF yield is slightly higher at higher inulin intakes, whereas the opposite trend is observed at higher temperatures, where a lower inulin intake is favoured.

The occurrence and importance of the consecutive reaction of HMF to LA was also confirmed by considering the LA yield $\left(\mathrm{y}_{\mathrm{LA}}\right)$ versus the process conditions (Table 3 ). The LA yield was modeled and the results are given in Figure 4 and Table 5 . The model equation with an R-square of 0.9464 is given in Eq. (5). An extended version with more significant numbers for the coefficients to be used for among others reactor engineering studies is given in the Additional file 1 . The parity plot (Figure 5) reveals good agreement between the model and the experimental data.

$$
\begin{aligned}
\mathrm{y}_{\mathrm{LA}}= & 437.51+(0.09) \mathrm{t}+(0.17) \mathrm{C}_{\mathrm{in}} \mathrm{t}+\left(5.88 .10^{-4}\right) \mathrm{Tt} \\
& +(1422.29) \mathrm{C}_{\mathrm{in}}^{2}+(0.02) \mathrm{T}^{2}-(188.89) \mathrm{C}_{\text {in }} \\
& -(5.41) \mathrm{T}-(0.12) \mathrm{C}_{\mathrm{in}} \mathrm{T}-\left(1.69 .10^{-3}\right) \mathrm{t}^{2}
\end{aligned}
$$

As expected on the basis of the reaction network proposed in Scheme 2, the LA yield is higher when using a longer batch time and higher temperatures, see Figure 4 for details.

\section{Possible role of acid formation on HMF yields: autocatalytic effects}

During the course of the reactions, organic acids such LA and FA are formed. These acids may act as catalysts for all reactions in the proposed reaction network (Scheme 2). To gain insight in the effect of these organic acids on the reaction rates and product distributions, a number of additional batch experiment was performed using inulin as the starting material and with one of the individual acids (LA or FA) and a combination of LA and FA present at the start of the reaction. The experiments were carried out temperature of $180^{\circ} \mathrm{C}$, an acid concentration of $0.1 \mathrm{M}$, and an inulin loading of $0.1 \mathrm{~g} / \mathrm{mL}$. The results are given in Figure 6.

When considering the fructose yield versus time profiles, it is evident that the presence of particularly FA has a positive effect on the rate of reaction of fructose and all fructose reacts away considerably faster when compared to the uncatalysed reaction and the reaction in the presence of LA. A similar trend was found for the HMF yield versus time profiles. Here the presence of FA also leads to a reduction of the time required to reach the maximum HMF yield. The autocatalytic effect of LA is by far 

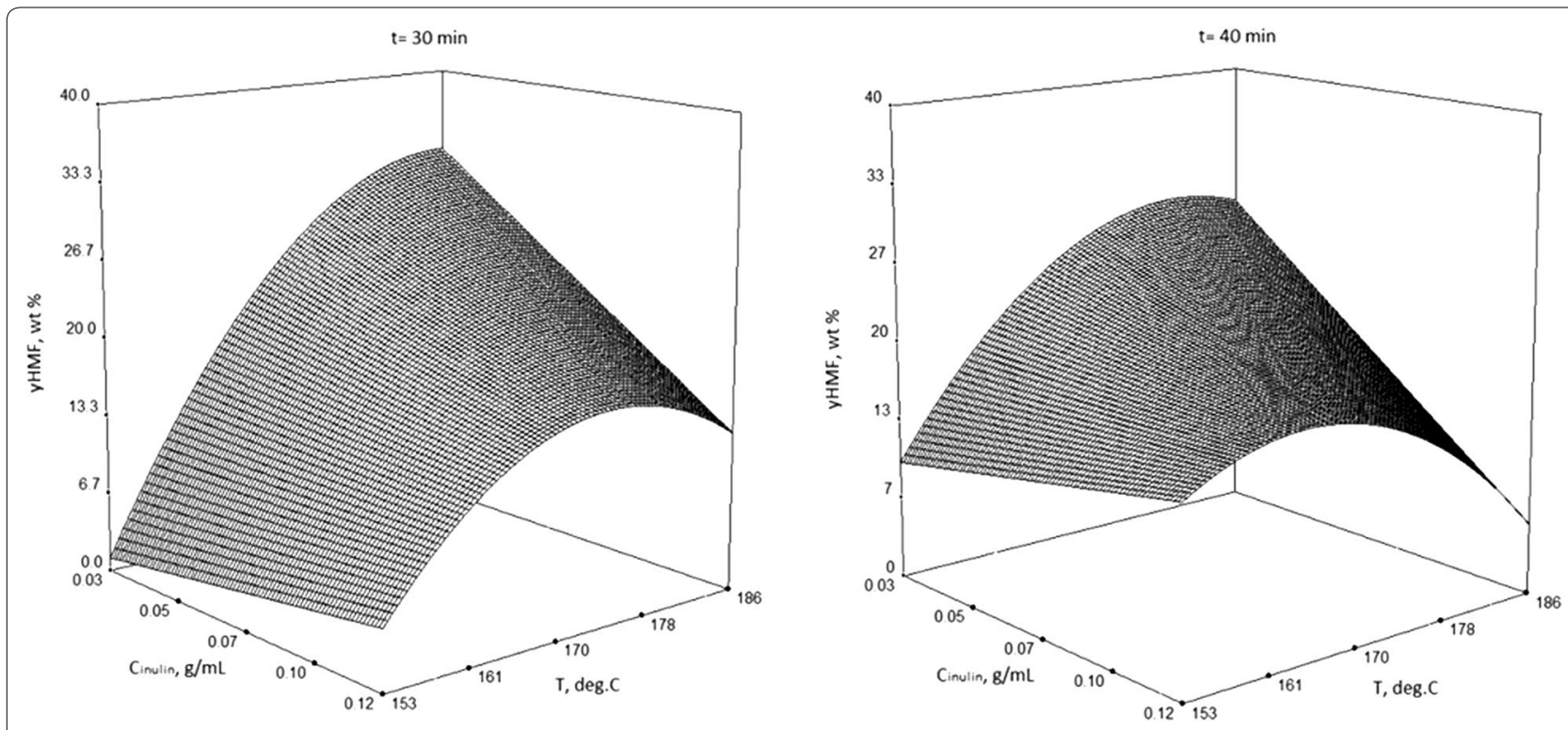

Figure 3 Modeled HMF yield versus temperature and inulin intake for two batch times (left 30 min; right 40 min).

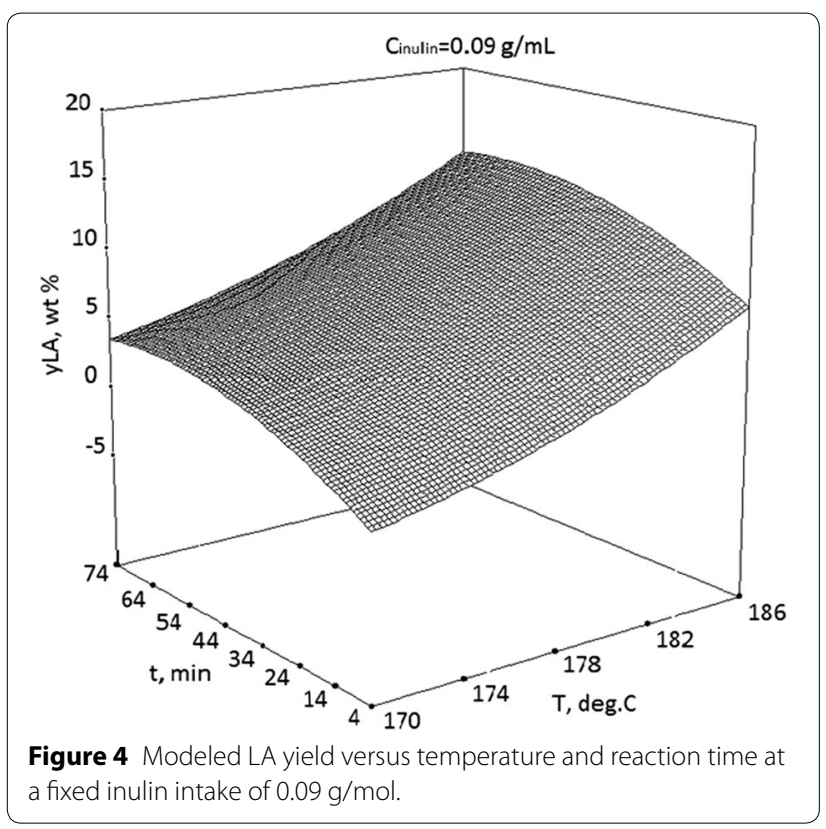

less pronounced than for FA and the profiles are essentially similar to the uncatalysed reaction. This, we may conclude that particularly FA has a positive effect on the reaction rates. These findings may be explained by considering the pKA values of both acids, 3.75 for FA and 4.6 for LA, indicating that a stronger Brönsted acid leads to higher reaction rates due to a higher Brönsted acidity of the solution. Thus, the formation of D-fructose and HMF is mainly due to autocatalytic effects of FA. These findings are in line with studies reported in the literature
Table 5 Analysis of variance of the LA model

\begin{tabular}{lllllr}
\hline Source & Sum of squares & df & Mean square & F value & $\begin{array}{r}\text { p value } \\
\text { Prob }>\text { F }\end{array}$ \\
\hline Model & 273.91 & 9 & 30.43 & 27.44 & $<0.0001$ \\
$C_{\text {in }}(A)$ & 1.29 & 1 & 1.29 & 1.16 & 0.2989 \\
$T(B)$ & 157.95 & 1 & 157.95 & 142.42 & $<0.0001$ \\
$t(C)$ & 25.28 & 1 & 25.28 & 22.79 & 0.0003 \\
$A B$ & $8.95 \times 10^{-3}$ & 1 & $8.95 \times 10^{-3}$ & $8.07 \times 10^{-3}$ & 0.9297 \\
$A C$ & 0.08 & 1 & 0.09 & 0.079 & 0.7829 \\
$B C$ & 0.15 & 1 & 0.15 & 0.14 & 0.7151 \\
$A^{2}$ & 14.29 & 1 & 14.29 & 12.88 & 0.0030 \\
$B^{2}$ & 43.84 & 1 & 43.84 & 39.53 & $<0.0001$ \\
$C^{2}$ & 4.97 & 1 & 4.97 & 4.48 & 0.0527 \\
Residual & 15.53 & 14 & 1.11 & & \\
\hline
\end{tabular}

using fructose as the substrate (Table 2). For instance Ranoux et al. [45], showed that the reaction of fructose to HMF is autocatalysed by FA and that the role of LA is by far less pronounced.

An interesting observation is that the maximum HMF yield in the yield-time profile is only slightly dependent on the presence of the organic acids, though evidently the reaction rates are affected. This also seems to be the case for D-fructose, though this is less clear as the fructose concentration may already have reached a maximum before the first sampling point $(15 \mathrm{~min})$. Both fructose and HMF are intermediates in the reaction network as given in Scheme 2. The near time independency of the maximum HMF yields as given in Figure 6 (right) 


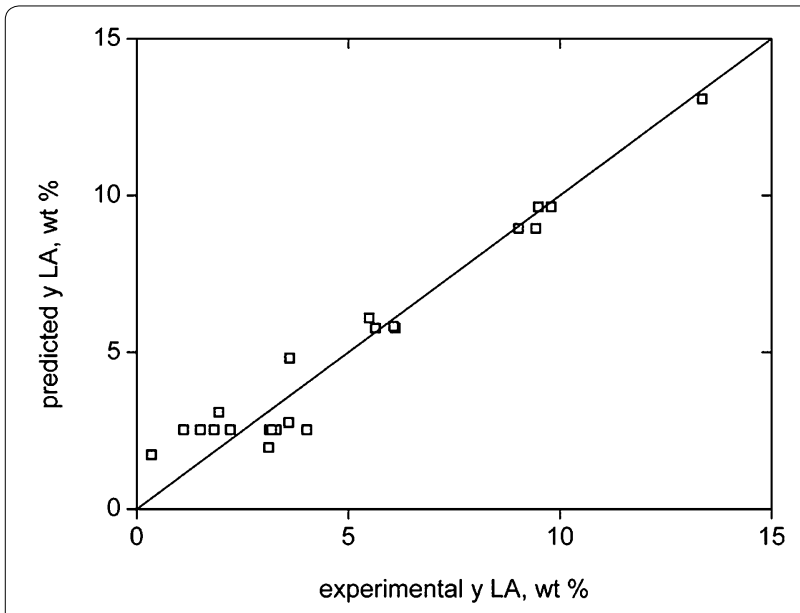

Figure 5 Parity plot between the experimental and modeled LA yield.

suggests that both the rates of inulin hydrolysis to fructose (with oligomeric intermediates), the subsequent formation of HMF and the subsequent reaction to LA and FA are equally affected by the presence of FA, implying a similar reaction order in $\mathrm{H}^{+}$(likely close to 1 ) [55].

However, without detailed kinetic studies (including determination of the amount of oligomeric sugars during reaction) it is not possible to draw definite conclusions about the exact mode of action of the organic acids and the way they influence reaction rates and thus the product yields. In addition, also for the thermal reaction, the organic acids are formed in the course of the reaction, resulting in autocatalytic effects that substantially complicate a detailed kinetic analysis.

\section{Conclusions}

The uncatalysed, thermal conversion of inulin to HMF in water was studied for a wide range of reaction conditions, including variations in temperature $\left(153-187^{\circ} \mathrm{C}\right)$, inulin intake $(0.03-0.12 \mathrm{~g} / \mathrm{mL})$ and reaction time (18-74 $\mathrm{min})$. Inulin was selected as it contains mainly D-fructose units, which are known to be among the best sugars for HMF synthesis. In addition, inulin has found a wide range of applications, among others, in the food and beverage industry and as such is abundantly available. The global inulin market was 246.5 kilo tons in 2013 and is expected to grow to exceed over 400 kilo tons by 2020 [58].

The highest HMF yield was $35 \mathrm{wt} \%$, corresponding to a $45 \%$ yield on a molar basis $\left(180^{\circ} \mathrm{C}\right.$, inulin intake of $0.05 \mathrm{~g} /$ $\mathrm{mL}$ and a reaction time of $18 \mathrm{~min})$. The experimental data were modelled using a statistical approach. The model shows a good fit with the experimental data and allows estimation of the HMF yield as a function of temperature, inulin intake and reaction time. This model may be used for reactor engineering purposes, for instance to optimise the HMF yield in continuous reactors with different degrees of mixing.

Autocatalysis of reaction products (FA and LA) and particularly by FA, the strongest acid, occurs to a significant extent as was shown by separate experiments with inulin in the presence of organic acids. These findings indicate that it may be advantageous regarding HMF yield to perform the reaction in a buffer solution at neutral $\mathrm{pH}$ values. These experiments are in progress and will be reported in due course.

Outlook: Besides the use of purified inulin, it also of interest to study the uncatalysed reaction with a real feed containing a high inulin content in order to
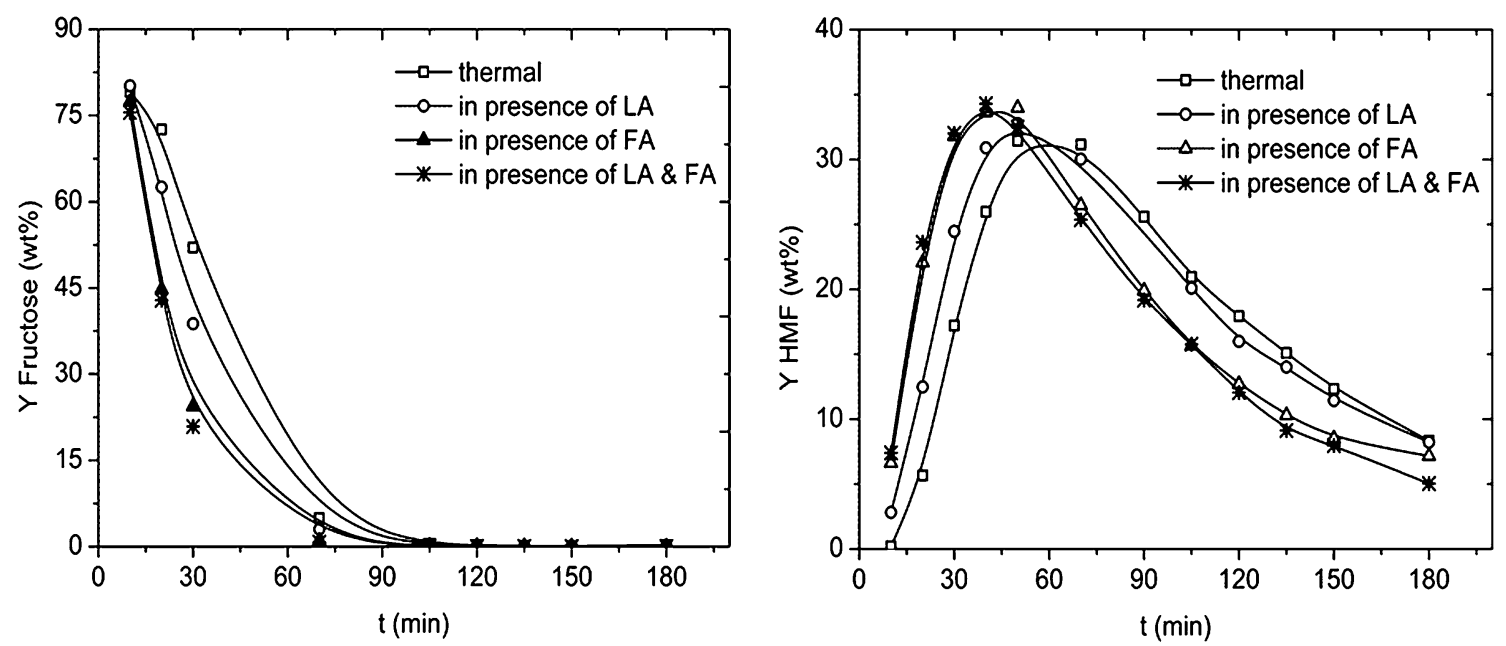

Figure 6 Autocatalytic effect of LA and formic acid on the fructose and HMF yield when using inulin as the feed (180 $\mathrm{C}$, an acid concentration of $0.1 \mathrm{M}$, and an inulin loading of $0.1 \mathrm{~g} / \mathrm{mL}$ ). 
further reduce the manufacturing costs of HMF. In this respect, the use of Chicory roots as a starting material for HMF production in water is of particular interest as this root has a reported inulin content of up to $20 \%$ on dry matter [32]. In addition, it is considered the best crop for inulin production as it has a high inulin yield per hectare (reported between 2.6 and 13.1 ton/ ton drymatter chicory roots per hectare [59]) and a regular root facilitating mechanic harvesting. The catalyzed version was reported in a patent from the Süddeutsche Zucker-Aktiengesellschaft, who showed an HMF yield of $13 \%$ when using chicory roots for a reaction in water with sulphuric acid as the catalyst ( $\mathrm{pH}$ of 1.8 at $140^{\circ} \mathrm{C}$ for $2 \mathrm{~h}$ [60]. Further studies will be required to show the proof of concept for the uncatalysed reaction.

\section{Additional files}

Additional file 1: The following additional data are available with the online version of this paper. Extended model equations of both the HMF and LA yield versus process parameters.

\section{Authors' contributions}

BAF and RMA carried out the experiments and drafted the manuscript. CBR and $\mathrm{HJH}$ supervised the entire study. All authors read and approved the final manuscript.

\section{Author details}

${ }^{1}$ Chemical Engineering Department, University of Groningen, Nijenborgh 4, 9747 AG Groningen, The Netherlands. ${ }^{2}$ Chemical Engineering Department, Faculty of Industrial Technology, Institut Teknologi Bandung, Ganesha 10, Bandung, Indonesia. ${ }^{3}$ Faculty of Engineering, University of Jember, Kalimantan 37, Jember, Indonesia.

\section{Acknowledgement}

B.A. Fachri and R.M. Abdilla would like to thank the Directorate General of Higher Education, Ministry of Education and Culture, Indonesia for funding of their PhD program.

\section{Compliance with ethical guidelines}

\section{Competing interests}

The authors declare that they have no competing interests.

Received: 10 February 2015 Accepted: 11 May 2015

Published online: 25 June 2015

\section{References}

1. Werpy T, Petersen G (2004) Top value added chemicals from biomass. US Department of Energy, Springfield

2. Bozell JJ, Petersen GR (2010) Technology development for the production of biobased products from biorefinery carbohydrates - the US department of energy's "top 10" revisited. Green Chem 12:539-554

3. Li C, Zhang Z, Zongbao ZK (2009) Direct conversion of glucose and cellulose to 5-hydroxymethylfurfural in ionic liquid under microwave irradiation. Tetrahedron Lett 50:5403-5405

4. Roman-Leskhov Y, Barret J, Liu ZY, Dumesic JA (2007) Production of dimethylfuran for liquid fuels from biomass-derived carbohydrates. Nature 447:982-986
5. Lewkowski J (2001) Synthesis, chemistry and applications of 5-hydroxymethylfurfural and its derivative. ARKIVOC (i):17-54

6. Corma A, Velty A, Sara I (2007) Chemical routes for the transformation of biomass into chemicals. Chem Rev 107:2411-2502

7. Chheda JN, Huber GW, Dumesic JA (2007) Liquid-phase catalytic processing of biomass-derived oxygenated hydrocarbons to fuels and chemicals. Angew Chem 46:7164-7183

8. Boisen A, Christensen T, Fu W, Gorbanev YY, Hansen TS, Jensen JS et al (2009) Process integration for the conversion of glucose to 2,5-furandicarboxylic acid. Chem Eng Res Des 87:1318-1327

9. van Putten RJ, van der Waal JC, de Jong E, Rasrendra $C B$, Heeres HJ, de Vries JG (2013) Hydroxymethylfurfural, a versatile platform chemical made from renewable resources. Chem Rev 113:1499-1597

10. Mednick ML (1962) The Acid-base-catalyzed conversion of aldohexose into 5-(hydroxymethyl)-2-furfural. National Meeting of the American Chemical Society, Chicago

11. McKibbins S, Harris J, Saeman J (1962) Kinetics of the acid catalyzed conversion of glucose to 5-hydroxymethyl-2-furadehyde and levulinic acid. For Prod J Part V 12:17-23

12. Kuster BFM (1977) The influence of water concentration on the dehydration of D-fructose. Carbohydr Res 54:177-183

13. Kuster BFM, Baan HSVD (1977) The influence of the initial and catalyst concentrations on the dehydration of $\mathrm{D}$-fructose. Carbohydr Res 54:165-176

14. Kuster BFM, Temmink HMG (1977) The Influence of pH and weak-acid anions on the dehydration of D-fructose. Carbohydr Res 54:185-191

15. Rapph K (1988) Process for preparing pure 5-hydroxymethylfuraldehyde. Patent No. US 4740605, Germany

16. Seri K, Inoue Y (2001) Catalytic activity of lanthanide(iii) ions for the dehydration of hexose to 5-hydroxymethyl-2-furaldehyde in water. Bull Chem Soc Jpn 74:1145-1150

17. Bicker M, Hirth J, Vogel H (2003) Dehydration of fructose to 5-hydroxymethylfurfural in sub and supercritical acetone. Green Chem 5:280-284

18. Watanabe M, Aizawa Y, lida T, Aida TM, Levy C, Sue K et al (2005) Glucose reactions with acid and base catalysts in hot compressed water at $473 \mathrm{~K}$. Carbohydr Res 340:1925-1930

19. Girisuta B, Janssen LM, Heeres HJ (2006) A Kinetic study on the conversion of glucose to levulinic acid. Chem Eng Res Des 84(A5):339-349

20. Tarabanko V, Chernyak MY, Nepomnyashchiy I, Smirnova MA (2006) High temperature 5-hydroxymethylfurfural synthesis in a flow reactor. Chem Sustain Dev 14:49-53

21. Kuster BFM (1990) 5-Hydroxymethylfurfural. A review focussing on its manufacturing. Starch/Starke 42:314-321

22. Newth FH (1951) The formation of furan compounds from hexoses. Adv Carbohydr Chem 6:83-106

23. Musau RM, Munavu RM (1987) The preparation of 5-hydroxymethyi2-furaldehyde (HMF) from D-fructose in the presence of DMSO. Biomass 13:67-74

24. Amarasekara AS, Ebede CC (2008) Mechanism of the dehydration of d-fructose to 5-hydroxymethylfurfural in dimethyl sulfoxide at $150^{\circ} \mathrm{C}$ : an NMR study. Carbohydr Res 343:3021-3024

25. Torres Al, Daoutidis P, Tsapatsis M (2010) Continuous production of 5-hydroxymethylfurfural from fructose: a design case study. Energy Environ Sci 3:1560-1572

26. Rosatella AA, Simeonov SP, Frade RFM, Afonso CAM (2011) 5-Hydroxymethylfurfural (HMF) as a building block platform: biological properties, synthesis and synthetic applications. Green Chem 13:754-793

27. Praznik W, Beck R (1984) Determination of fructan oligomers of degree of polymerization 2-30 by high-performance liquid chromatography. J Chromatogr 303:417-421

28. Bohm A, Kaiser I, Trebstein A, Henle T (2005) Heat-induced degradation of inulin. Eur Food Res Technol 220:466-471

29. Kays SJ, Nottingham SF (2008) Biology and chemistry of jerusalem artichoke. CRC Press, Taylor \& Francis Group, Boca Raton

30. Franck A (2002) Technological functionality of inulin and oligofructose. $\mathrm{Br}$ J Nutr 87:S287-S291

31. Roberfroid M (2005) Inulin-type of fructans. CRC Press, Boca Raton

32. Ricca E, Calabro V, Curcio S, lorio G (2007) Fructose production by chicory inulin enzymatic hydrolysis: a kinetic study and reaction mechanism. Process Biochem 2007(44):466-470 
33. Hu Z, Liu B, Zhang Z, Chen $L$ (2013) Conversion of carbohydrates into 5-hydroxymethylfurfural catalyzed by acidic ionic liquids in dimethyl sulfoxide. Ind Crop Prod 50:264-269

34. Wu S, Fan $\mathrm{H}$, Xie $Y$, Cheng $Y$, Wang Q, Zhang Z et al (2010) Effect of $\mathrm{CO}_{2}$ on conversion of inulin to 5-hydroxymethylfurfural and propylene oxide to 1 , 2-propanediol in water. Green Chem 12:1215-1219

35. Benvenuti F, Carlini C, Patrono P, Raspolli Galletti AM, Sbrana G, Massucci MA et al (2000) Heterogeneous zirconium and titanium catalysts for the selective synthesis of 5-hydroxymethyl-2-furaldehyde from carbohydrates. Appl Catal A Gen 193:147-153

36. Carlini C, Patrono P, Gallettia AMR, Sbrana G (2004) Heterogeneous catalysts based on vanadyl phosphate for fructose dehydration to 5-hydroxymethyl-2-furaldehyde. Appl Catal A Gen 2004(275):111-118

37. Wu Q, Yan Y, Zhang Q, Lu J, Yang Z, Zhang Y et al (2013) Catalytic dehydration of carbohydrates on in situ exfoliatable layered niobic acid in an aqueous system under microwave irradiation. Chem Sustain Chem 6:820-825

38. Carlini C, Giuttari M, Galletti AMR, Sbrana G, Armaroli T, Busca G (1999) Selective saccharides dehydration to 5-hydroxymethyl-2-furaldehyde by heterogeneous niobium catalysts. Appl Catal A Gen 183:295-302

39. Savage PE (1999) Organic chemical reactions in supercritical water. Chem Rev 99:603-621

40. Akiya N, Savage PE (2002) Roles of water for chemical reactions in hightemperature water. Chem Rev 102:2725-2750

41. Oomori T, Khajavi SH, Kimura Y, Adachi S, Matsuno R (2004) Hydrolysis of disaccharides containing glucose residue in subcritical water. Biochem Eng J 2004(18):143-147

42. Kruse A, Dinjus E (2007) Hot compressed water as reaction medium and reactant properties and synthesis reactions. J Supercrit Fluids 39:362-380

43. Hansen TS, Woodley JM, Riis A (2009) Efficient microwave-assisted synthesis of 5-hydroxymethylfurfural from concentrated aqueous fructose. Carbohydr Res 344:2568-2572

44. Qi X, Watanabe M, Aida TM, Smith RL Jr (2008) Catalytical conversion of fructose and glucose into 5-hydroxymethylfurfural in hot compressed water by microwave heating. Catal Commun 9:2244-2249

45. Ranoux A, Djanashvili K, Arends IWCE, Hanefeld U (2013) 5-Hydroxymethylfurfural synthesis from hexoses is autocatalytic. ACS Catal 3:760-763

46. Harvey DJ (1996) Matrix-assisted laser desorption/ionisation mass spectrometry of oligosaccharides and glycoconjugates. J Chromatogr A 720:429-446
47. Kazmaier T, Roth S, Zapp J, Harding M, Kuhn R (1998) Quantitative analysis of malto-oligosaccharides by MALDI-TOF mass spectrometry, capillary electrophoresis and anion exchange chromatography. Fresenius J Anal Chem 361:473-478

48. Anan'ina NA, Andreeva OA, Mycots LP (2009) Standarization of inulin extracted from dahlia single tubers and some physicochemical properties of inulin. Pharm Chem J 43:157-158

49. Khajavi SH, Kimura Y, Oomori T, Matsuno R, Adachi S (2005) Degradation kinetics of monosaccharides in subcritical water. J Food Eng 68:309-313

50. Aida TM, Tajima K, Watanabe M, Saito Y, Kuroda K, Nonaka T et al (2007) Reactions of D-fructose in water at temperatures up to $100 \mathrm{MPa}$. J Supercrit Fluids 42:110-119

51. Aida TM, Sato Y, Watanabe M, Tajima K, Nonaka T, Hattori H et al (2007) Dehydration of D-glucose in high temperature water at pressures up to $80 \mathrm{MPa}$. J Supercrit Fluids 40:381-388

52. Brunner G (2009) Near critical and supercritical water. Part I. Hydrolytic and hydrothermal processes. J Supercrit Fluids 47:373-381

53. Jin FM, Zhou ZY, Moriya T, Kishida H, Higashijima H, Enomoto H (2005) Controlling hydrothermal reaction pathways to improve acetic acid production from carbohydrate biomass. Environ Sci Technol 39:1893-1902

54. Asghari SF, Yoshida H (2006) Acid-catalyzed production of 5-hydroxymethyl furfural from D-fructose in subcritical water. Ind Eng Chem Res 45:2163-2173

55. Fachri BA, Abdilla RM, Rasrendra CB, Heeres HJ (2015) Experimental and modeling studies on the acid-catalysed conversion of inulin to 5-hydroxymethylfurfural in water. Chem Eng Res Des (submitted)

56. De S, Dutta S, Saha B (2011) Microwave assisted conversion of carbohydrates and biopolymers to 5-hydroxymethylfurfural with aluminium chloride catalyst in water. Green Chem 12:1215-1219

57. Li Y, Lu X, Yuan L, Liu X (2009) Fructose decomposition kinetics in organic acids-enriched high temperature liquid water. Biomass Bioenergy 33:1182-1187

58. http://www.grandviewresearch.com/press-release/global-inulin-market. Accessed April 26, 2015

59. http://www.eblex.org.uk/wp/wp-content/uploads/2013/12/BRPplusChicory-and-Plantain031213.pdf. Accessed April 26, 2015

60. Rapp K (1988) Process for preparing pure 5-hydroxymethylfuraldehyde. US Patent No. 4740605

\section{Publish with ChemistryCentral and every scientist can read your work free of charge \\ "Open access provides opportunities to our colleagues in other parts of the globe, by allowing anyone to view the content free of charge."}

W. Jeffery Hurst, The Hershey Company.

- available free of charge to the entire scientific community

- peer reviewed and published immediately upon acceptance

- cited in PubMed and archived on PubMed Central

- yours - you keep the copyright

Submit your manuscript here:

http://www.chemistrycentral.com/manuscript/<smiles>c1ccccc1</smiles>

ChemistryCentral 